\title{
Role of Personal Cultural Orientations in Intercultural Service Encounters
}

Purpose - In this paper, we address a major gap in current research by exploring the direct and indirect effects of four personal cultural orientations (independence, interdependence, risk aversion and ambiguity intolerance) in intercultural service encounters.

Design/methodology/approach -2 X 2 between-subjects experimental design with customers in two countries (Australia and China) using scenarios to manipulate service outcome (failure or success) and photos of foreigners as customer or employee to prime perceived cultural distance. Findings - Customers with higher (vs. lower) independence perceive greater interaction comfort, service quality and satisfaction, and are affected to a lesser extent by perceived cultural distance and service outcome; but those with higher (vs. lower) risk aversion or ambiguity intolerance perceive lower interaction comfort, service quality and satisfaction, and are affected more strongly by perceived cultural distance and service outcome.

Research limitations/implications - We used an 'experimental' design with 'imaginary' service scenarios to collect data in 'two' countries using 'four' personal cultural orientations for greater control in our study but all of these choices may restrict the generalizability of our findings. Practical implications - Service managers need to look beyond visible cultural differences such as ethnicity, nationality and language, and focus more on the invisible cultural differences in customs, values and norms, as reflected by the four personal cultural orientations in our study. Originality/value - We extend prior research by exploring the moderating effects of personal cultural orientations on the influence of service outcome and perceived cultural distance on interaction comfort, service quality and satisfaction, in intercultural service encounters.

Keywords - Independence, Interdependence, Risk Aversion, Ambiguity Intolerance, Interaction Comfort, Intercultural Service Encounter, Perceived Cultural Distance, Quality, Satisfaction Paper type - Research paper 


\section{Role of Personal Cultural Orientations in Intercultural Service Encounters}

\section{INTRODUCTION}

With rapid globalization, the number of people traveling abroad for business, education, employment, migration and tourism has grown dramatically in recent years; resulting in an unprecedented increase in the number of interactions among people from different cultures (Etgar and Fuchs, 2011; Teng, 2011; Wang and Mattila, 2010). While such intercultural interactions expose people to other cultures, it can be a big challenge to motivate people to learn about other cultures, accept their cultural differences and adapt their own behavior via the process of acculturation (Berry, 1974, 2005) or cross-cultural adjustment (Ward and Kennedy, 2001; Ward and Rana-Deuba, 2000). Cross-cultural contact is also associated with ethno-cultural identity conflict (Leong and Ward, 2000; Ward, 2008) and problems such as misattributions, communication gaps, stereotyping, ethnocentrism, prejudice and discrimination (Stening, 1979) as well as emotional labor, surface acting and inter-group anxiety (Chuapetcharasopon, 2014).

In view of the above, it is not surprising to see a growing interest in services marketing literature, on intercultural service encounters (ICSE) in which customers and employees from different cultures interact with each other (Sharma, Tam and Kim, 2009, 2012, 2015). Marketing academics and practitioners have begun to recognize intercultural service encounter as inevitable outcomes of globalization and ubiquitous features of an increasingly diverse global marketplace (Demangeot, Broderick and Craig, 2015; Tam, Sharma and Kim, 2014). There is also a growing acknowledgement of the need to understand the challenges posed by the differences in the perceptions, expectations and evaluations of customers and employees from diverse cultural backgrounds (Chuapetcharasopon, 2014; Sharma et al., 2015; Sharma and Zhan, 2015). 
Despite the growing literature on intercultural service encounters, there is hardly any research that directly examines the impact of cultural factors (e.g., personal cultural orientations) of customers or employees on their perceptions, evaluations and behaviors in intercultural service encounters. As a result, while we know that there are differences in the way perceived cultural distance among the customers and the employees affects their expectations, perceptions and behaviors in intercultural service encounters, there is no direct evidence about how different aspects of culture drive these differences (Gap 1). For example, we know that the customers from individualistic cultures tend to focus more on the objective aspects of service quality such as reliability, responsiveness and tangibles, whereas those from collectivistic cultures focus more on subjective criteria such as empathy and assurance (Donthu and Yoo, 1998; Furrer, Liu and Sudharshan, 2000; Mattila, 1999), however it is not clear how these differences would affect the interaction between a customer and an employee from these contrasting cultural backgrounds.

In addition, prior research on the impact of culture on customer expectations, perceptions and evaluations, generally focuses on service failures and ignores successful service encounters (e.g., Donthu and Yoo, 1998; Furrer et al., 2000; Mattila, 1999), whereas in intercultural service encounters even successful outcomes may leave some customers dissatisfied especially those with lower levels of intercultural competence (Sharma, Tam, et al., 2012; Sharma et al., 2015). Hence, we need to study the differences in the impact of cultural factors between intercultural service encounters with service failure and success (Gap 2). Finally, most studies in this research area use Hofstede's (2001) national cultural dimensions to conceptualize and measure cultural factors at individual level (e.g., Donthu and Yoo, 1998; Furrer et al., 2000; Kueh and Voon, 2007; Tsoukatos and Rand, 2007), an approach that suffers from ecological fallacy, assumes cultural factors to be unidimensional constructs and provides little or no evidence of construct validity 
and measurement equivalence of these scales (Gap 3). Hence, we need to use recent perspectives that more accurately reflect individual level cultural values and orientations (e.g., Sharma, 2010).

We address all these research gaps, by combining the existing knowledge about crosscultural differences in the customers' service expectations (Donthu and Yoo, 1998; Kueh and Voon, 2007), perceptions (Furrer et al., 2000; Tsoukatos and Rand, 2007) and evaluations (Crotts and Erdmann, 2000) with recent work on the measurement of culture through personal cultural orientations (e.g., Sharma, 2010). We develop a conceptual framework with specific hypotheses about the moderating effects of four personal cultural orientations of customers (independence, interdependence, risk aversion and ambiguity intolerance) on the impact of perceived cultural distance and service outcome (failure vs. success) on interaction comfort in intercultural service encounters, while controlling for the effects of consumer ethnocentrism, intercultural competence and demographics (gender, age, ethnicity and work experience). Next, we report findings from a large-scale study with a customers from diverse cultural backgrounds in two countries (Australia and China), using an experimental approach to manipulate perceived cultural distance and service outcome. Finally, we discuss the conceptual contribution, managerial implications and limitations of our findings along with directions for future research.

\section{CONCEPTUAL FRAMEWORK AND HYPOTHESES}

\section{Perceived Cultural Distance (PCD)}

Perceived cultural distance is defined as the extent to which people from one culture perceive those from other cultures to be different in terms of their ethnicity, nationality, language, values and customs (Sharma et al., 2009). Lower PCD should facilitate interpersonal communication between service customers and employees from different cultural backgrounds and improve their 
understanding of each other's expectations; whereas higher PCD has exactly the opposite impact. However, there is mixed evidence about the role of perceived cultural distance in intercultural service encounters, with some showing a negative impact of PCD on customer preferences (AliSulaiti and Baker, 1998; Harrison-Walker, 1995; Hopkins, Hopkins and Hoffman, 2005; Kulik and Holbrook, 2000), whereas others show a positive influence of PCD on customer expectations (Weiermair, 2000), interaction comfort (Sharma, Tam, et al., 2012) and satisfaction (Stauss and Mang, 1999; Warden, Liu and Huang, 2003). We argue that one of the reasons for these mixed findings could be that most of these studies operationalized PCD as an overall difference in the nationality or ethnicity of the customers and employees involved in intercultural service encounters, rather than actually tapping into the differences in their individual cultural values or orientations. We address this gap by exploring the direct and indirect effects of four personal cultural orientations (independence, interdependence, risk aversion and ambiguity intolerance). However, we first hypothesize a main negative effect of PCD on interaction comfort, a psychological state experienced by customers during a service encounter, feeling calm and comfortable under high IC and anxious, worried or insecure under low IC (Spake et al., 2003).

H1: Perceived cultural distance has a negative effect on interaction comfort.

\section{Service Outcome (Failure vs. Success)}

Prior research on intercultural service encounters mostly explores service failures (e.g., Sharma, Tam, et al., 2012; Stauss and Mang, 1999; Wang and Mattila, 2011; Warden et al., 2003; Weiermair, 2000) possibly because customers do not think too much about successful service encounters (Oliver, Rust and Varki, 1997); whereas service failures make customers uneasy and prompt them to try and analyze these in order to resolve their psychological discomfort (Laufer, 
2002). Therefore, we argue that customers would experience a higher level of interaction comfort in successful intercultural service encounters and a lower level of interaction comfort in service failures because of their poor service experience. Accordingly, we hypothesize:

H2: Service failure (success) has a negative (positive) effect on interaction comfort.

\section{Personal Cultural Orientations (PCO)}

Culture represents shared knowledge and implicit theories about the world and it includes a wide range of attitudes, beliefs and values that we need to interpret and navigate in the complex and diverse social environments (Hong et al., 2000). Cultural knowledge consists of various rules and guidelines that are used by people to define their social realities and these are transmitted to future generations through the socialization process (Lau, Chiu and Lee, 2001). There is growing research interest in measuring the impact of culture on consumer attitudes and behavior due to an increase in the diversification of consumer segments and rapid expansion of global brands and marketing companies triggered by the rise in globalization (Douglas and Craig, 1997). However, the role of culture itself, at either national or personal level, has not been systematically investigated in the context of intercultural service encounters, leaving a gap in literature.

Prior research in marketing mostly used Hofstede's $(1980,1991,2001)$ cultural framework to explore cross-cultural differences in consumer behavior as it provided a wellestablished theoretical foundation. Hofstede (1980) began with four original dimensions (individualism-collectivism, power distance, masculinity/femininity, and uncertainty avoidance) to which he added a fifth dimension (long vs. short-term orientation) with Bond (1988) but renamed it as 'pragmatism vs. normative' with Minkov (2010). He also added a sixth dimension (indulgence vs. restraint) with others (Hofstede, Hofstede and Minkov, 2010). Despite the 
popularity of Hofstede's cultural framework there is growing evidence that most societies have people with a diverse range of cultural values (Schwartz, 1994) and most people can adapt to culturally appropriate behavior in given situations (Oyserman, Kemmelmeier and Coon, 2002).

Notwithstanding the above, marketing researchers have either assumed Hofstede's national culture dimension to be equally applicable at individual level (e.g., Albers-Miller and Gelb, 1996; Birgelen et al., 2002; Laroche et al., 2004; Sivakumar and Nakata, 2001; Steenkamp, Hofstede and Wedel, 1999) or simply adapted a few items from Hofstede's original scales to operationalize his national cultural dimensions at individual customer's level (e.g., Donthu and Yoo, 1998; Dorfman and Howell, 1988; Erdem, Swait and Valenzuela, 2006; Furrer et al., 2000; Hui, 1988; Jung and Kellaris, 2006; Lee and Lim, 2008; Yoo and Donthu, 2005). However, most of them simply assume Hofstede's national cultural dimensions to be applicable at individual level with no evidence of the content or construct validity of these reduced or adapted scales. For example, CVSCALE (Donthu and Yoo, 1998; Yoo and Donthu, 2005; Yoo, Donthu and Lenartowicz, 2011) includes only the collectivism dimension and treats individualism as its opposite; whereas these two are distinct cultural dimensions and should be measured separately (Oyserman, Coon and Kemmelmeier, 2002; Sharma, 2010).

As a result, it is not surprising to see mixed results in prior research on the influence of cultural factors on service quality expectations and perceptions. For example, Donthu and Yoo (1998) found no effect of uncertainty avoidance on tangibles and long-term orientation on responsiveness; whereas Furrer et al. (2000) shows no effect of masculinity on reliability, assurance and empathy. Similarly, Kueh and Voon (2007) found no effect of masculinity whereas Tsoukatos and Rand (2007) found long-term orientation related to only the reliability dimension of service quality; while others found very limited support for the effect of power 
distance, masculinity and long-term orientation on behavioral intentions (Liu, Furrer and Sudharshan, 2001). To address these concerns, Sharma (2010) recently reconceptualized and redefined Hofstede's five national cultural dimensions as ten personal cultural orientations (PCO) and used three large-scale studies to develop and test a new 40-item PCO scale to measure these individual level cultural factors. In this paper, we focus on four personal cultural orientations (i.e., independence, interdependence, risk aversion and ambiguity intolerance) out of ten, in order to keep our model simple and parsimonious in view of all the direct and moderating effects.

Independence (IND): According to Hofstede (2001; p. 225), in individualistic cultures the ties between individuals are loose and people are only expected to look after themselves and their immediate family; and individualism is similar to values such as power, achievement, and hedonism (Schwartz et al., 2001). Individualists also prefer to be independent rather than be known as members of groups and they typically possess a strong self-concept and sense of freedom with a greater focus on autonomy and personal achievement (Oyserman, Coon, et al., 2002). Prior cross-cultural studies mostly use Hofstede's (1980) perspective that individualism (IND) and collectivism (COL) are opposite of each other. However, others argue that people could maintain both independent and interdependent selves and either of these may be activated in any given situation (Markus and Kitayama, 1991). In view of the above, Sharma (2010) defines IND as a personal cultural orientation associated with acting independently, a strong selfconcept, a sense of freedom, autonomy, and personal achievement. According to him, independence is also similar to other cultural values such as competence (Bond, 1988), individualism and achievement (Trompenaars, 1993), self-direction and hedonism (Schwartz, 1994), and autonomy (Steenkamp, 2001). Thus, independence provides a more appropriate conceptualization of Hofstede's individualistic dimension at an individual level. 
Past research on the influence of culture on evaluation of service encounters shows that customers from individualistic cultures tend to rely more on the objective evaluation criteria such as reliability, responsiveness and tangibles, rather than subjective criteria such as empathy and assurance (Furrer et al., 2000; Mattila, 1999; Mattila and Patterson, 2004b). Based on this, we argue that customers with high levels of independence would not focus too much on their cultural differences with service employees in intercultural service encounters because these differences are highly subjective and not perceived as being related to service performance. Hence, customers with high scores on independence are likely to feel more comfortable during intercultural service encounters in general, which leads to our next hypothesis:

H3a: Independence has a positive effect on interaction comfort.

Prior research shows that cultural factors such as individualism-collectivism not only directly affect the various elements of customers' service experience (e.g., perceived value, service quality and satisfaction) but they also moderate the relationships among these variables (Sharma, Chen and Luk, 2012). Specifically, the positive relationships between service quality and satisfaction, perceived value and behavioral intentions are stronger for customers from collectivistic (vs. individualistic) cultures because they tend to rely more on intangible rather than tangible cues from the environment (Mattila, 1999) as well as subjective criteria such as empathy and assurance, rather than objective criteria such as reliability, responsiveness and tangibles (Furrer et al., 2000; Mattila, 1999; Mattila and Patterson, 2004b).

Based on the above, we argue that customers with higher levels of independence may not allow perceived cultural distance or a service failure, which are based on subjective perceptions and intangible cues, to bias their objective evaluation of an intercultural service encounter to a 
great extent. In contrast, customers with lower independence are more likely to experience lower interaction comfort with culturally distant service employees and in situations involving service failures, due to their greater focus on subjective and intangible cues and narrower zones of tolerance. In addition, successful service encounters would not show such stark differences in the influence of perceived cultural distance and service outcome on interaction comfort because customers do not generally pay much attention or look for attributions for successful service encounters (Sharma et al., 2015; Tam et al., 2014). Hence, we hypothesize as follows:

H3b: The negative effect of perceived cultural distance on interaction comfort is stronger for people with lower (vs. higher) independence.

H3c: The negative (positive) effect of service failure (success) on interaction comfort is stronger for people with lower (higher) independence.

Interdependence (INT): Hofstede (2001; p. 225) describes people in collectivistic cultures as being integrated from birth onwards into strong and cohesive in-groups, which continue to protect them in exchange for unquestioning loyalty throughout their lifetime. Collectivism is associated with values such as benevolence, tradition, and conformity (Schwartz et al., 2001) and other cultural values such as cultural inwardness, social reliability and morality (Bond, 1988), benevolence and conformity (Schwartz, 1994), and universalism (Smith, Dugan and Trompenaars, 1996). Collectivists see themselves as part of one or more in-groups and they are willing to give priority to the goals of these in-groups over their own personal goals. As explained earlier, prior studies using Hofstede's (1980) perspective that individualism (IND) and collectivism (COL) are opposite of each other, do not provide a correct picture of these two constructs at an individual level, because most people have both independent and interdependent selves and any of these could be activated at any given time (Markus and Kitayama, 1991). To 
address this issue, Sharma (2010) reconceptualizes collectivism as interdependence, a personal cultural orientation that includes "acting as a part of one or more in-groups, a strong group identity, a sense of belongingness, reliance on others, giving importance to group-goals over own individual goals and collective achievement".

Prior research on evaluation of service encounters shows that customers from collectivistic cultures tend to focus more on the subjective aspects such as attitudes and behavior of service employees (Donthu and Yoo, 1998). As a result, they may be more sensitive to cultural differences in intercultural service encounter setting, which are highly subjective in nature. Based on this we argue that customers with high levels of interdependence would be more likely to feel uncomfortable and outside their zone of familiarity in intercultural service encounters. Hence, we put forth the following hypothesis:

H4a: Interdependence has a negative effect on interaction comfort.

We also argue that the high interdependent customers would consider culturally distant employees that they may face during intercultural service encounters, to be outside their in-group and hence, feel even more uncomfortable dealing with them compared to interacting with culturally closer employees. In fact, their discomfort in dealing with culturally distant employees may also make them evaluate such employees even more unfavorably if the service encounter results in failure. In contrast, a successful service encounter may mitigate this effect by not attracting too much attention or attributions from the customers. Hence, we hypothesize:

H4b: The negative effect of perceived cultural distance on interaction comfort is stronger for people with higher (vs. lower) interdependence. 
H4c: The negative (positive) effect of service failure (success) on interaction comfort is stronger for people with higher (lower) interdependence.

Risk aversion (RSK): Hofstede (2001; p. 161) defines uncertainty avoidance (UAI) as the extent to which people feel threatened by ambiguous or unknown situations. People with high UAI try to avoid ambiguity and risk in any situation and prefer predictability, written explicit rules and structured situations; whereas lower UAI relates with a higher tolerance for ambiguity and propensity for risk taking (Hofstede, 2001). Individuals with lower UAI tend to be more active, emotional, and security-seekers; accepting uncertainty without much discomfort, and showing greater tolerance for opinions and behaviors different from their own (Triandis, 1999). In contrast, people with higher UAI are more contemplative, less emotional and low risk-takers; with a stronger need to control the environment, events and situations in their lives.

Prior research uses Hofstede's (2001) UAI as a unidimensional construct and fails to acknowledge that it has two distinct aspects - risk avoidance, the extent to which people do not like taking risks (Bontempo, Bottom and Weber, 1997; Keh and Sun, 2008); and intolerance of ambiguity, the degree to which individuals feel uncomfortable when confronted with ambiguity (de Mooij and Hofstede, 2002). Based on this, Sharma (2010) reconceptualizes UAI as two positively correlated dimensions, one of which he called risk aversion (RSK), the extent to which people are reluctant to take risk or make risky decisions. For example, customers may prefer to be served by those who are culturally or ethnically similar to them, to avoid the risk of dealing with a person who may not be familiar with their expectations and preferences (Ali-Sulaiti and Baker, 1998; Harrison-Walker, 1995; Hopkins et al., 2005; Kulik and Holbrook, 2000). 
Prior research shows that customers from high uncertainty avoidance cultures focus more on subjective aspects (Furrer et al., 2000) and have narrower zones of tolerance (Reimann, Lünemann and Chase, 2008). Therefore, we argue that customers with higher levels of risk aversion are more likely to consider intercultural service encounters as unfamiliar and fraught with high perceived risk, which would make them feel more uncomfortable. In contrast, people with lower levels of risk aversion may not find the unfamiliarity of an intercultural service encounter risky or uncomfortable, and in fact they may even like such experiences. Hence,

H5a: Risk aversion has a negative effect on interaction comfort.

We also argue that similar to high interdependent customers, those with high risk aversion may consider culturally distant service employees as being more unfamiliar and even unfriendly, making them feel really uncomfortable and result in unfavorable evaluations of service quality and customer satisfaction, especially in service failures. Additionally, they are more likely to respond to cross-cultural difference with strong negative attitudes and actions towards culturally distant employees as compared to customers with low levels of risk aversion who are more likely to understand and accommodate cross-cultural difference. Hence,

H5b: The negative effect of perceived cultural distance on interaction comfort is stronger for people with higher (vs. lower) risk aversion.

H5c: The negative (positive) effect of service failure (success) on interaction comfort is stronger for people with higher (lower) risk aversion.

Ambiguity Intolerance (AMB): Sharma (2010) defines ambiguity intolerance (AMB) as the degree to which people are not able to tolerate ambiguity and prior research distinguishes this from the tendency to avoid taking risks or avoiding uncertainty (Grenier, Barrette and Ladouceur, 
2005). Customers with higher scores on AMB evaluate products imported from other countries unfavorably because of ambiguous signals about their quality (Sharma, 2010). Such customers are also less satisfied when their service expectations are not met and they have narrower zones of tolerance compared to others (Reimann et al., 2008). We argue that intercultural service encounters present a high level of ambiguity because customers and employees may not know how to behave with each other in the most appropriate manner, due to their cultural differences (Sharma et al., 2009). For example, a smile or a touch from an employee with a different cultural background may be seen as an ambiguous message and may make customers with higher levels of intolerance for ambiguity feel greater discomfort. Hence, we hypothesize as follows:

H6a: Ambiguity intolerance has a negative effect on interaction comfort.

We argue that customers with higher levels of intolerance for ambiguity may not like to be served by the employees with greater perceived cultural distance because this would make them even more uncomfortable due to the high uncertainty about knowing each other's role expectations and motivations. We also expect this effect to be accentuated in service failure situations because customers with high intolerance for ambiguity would possibly blame the culturally distant employees for the service failure. Hence, we offer the following hypotheses:

H6b: The negative effect of perceived cultural distance on interaction comfort is stronger for people with higher (vs. lower) ambiguity intolerance.

H6c: The negative (positive) effect of service failure (success) on interaction comfort is stronger for people with higher (lower) ambiguity intolerance. 


\section{Perceived Service Quality (PSQ)}

Perceived service quality is defined as “a global judgment or attitude based on customers' beliefs about their service experience" (Parasuraman, Zeithaml and Berry, 1988) and it has a positive effect on customer satisfaction and behavioral intentions such as repeat purchase and positive word-of-mouth (Zeithaml, Berry and Parasuraman, 1996). Customers generally perceive lower level of service quality and greater discomfort in intercultural service encounters (AliSulaiti and Baker, 1998; Harrison-Walker, 1995; Hopkins et al., 2005; Kulik and Holbrook, 2000; Stauss and Mang, 1999; Warden et al., 2003; Weiermair, 2000). Recent studies show that it is the lower level of interaction comfort in intercultural service encounters that drives poor perceptions of service quality (Sharma, Tam, et al., 2012; Sharma et al., 2015). Hence, we hypothesize:

H7: Interaction comfort has a positive effect on perceived service quality.

\section{Satisfaction (SAT)}

Customer satisfaction is defined as an emotional state experienced in response to an evaluation of customer's experience in a service encounter and it is the ultimate objective of all marketers (Oliver, 1997). Customer satisfaction is driven by employee's effort (Mohr and Bitner, 1995 ) and performance during a service encounter (Dolen, Ruyter and Lemmink, 2004; Schneider and Bowen, 1985) and it in turn affects customer outcomes such as repeat purchase and loyalty (Seiders et al., 2005). Customers report lower level of satisfaction in intercultural service encounters because they do not think that the culturally distant service employee would be able to understand and meeting their expectations (Etgar and Fuchs, 2011; Sharma, Tam, et al., 2012; Ueltschy et al., 2007). Prior studies on intercultural service encounters show that customer satisfaction is influenced by interaction comfort (Paswan and Ganesh, 2005; Sharma and Zhan, 
2015), perceived service level (Sharma, Tam, et al., 2012) as well as perceived service quality (Sharma et al., 2015; Sharma and Zhan, 2015). Based on this, we also hypothesize as follows:

H8: Interaction Comfort has a positive effect on customer satisfaction.

H9: Perceived service quality has a positive effect on customer satisfaction.

Figure $1(\mathrm{H} 1-\mathrm{H} 9)$ summarizes all these hypotheses.

$<$ Insert Figure 1 about here $>$

\section{METHODOLOGY}

\section{Research Setting}

We chose Australia and China as the research setting for our empirical study because both these countries represent contrasting cultural values as reflected by the differences in their scores on Hofstede's national cultural dimensions (2010), namely individualism (90 vs. 20), power distance (36 vs. 80 ), uncertainty avoidance (51 vs. 30$)$, pragmatism (21 vs. 87 ) and indulgence (71 vs. 24) respectively. Moreover, both these countries report high levels of consumer ethnocentrism and lower levels of intercultural competence possibly due to a long history of geographical and cultural isolation in both Australia (Pecotich and Rosenthal, 2001) and China (Wang and Chen, 2004). As a result, it is not surprising to see that ethnic minorities report unfriendliness, embarrassment, neglect and lack of trust from local service providers in Australia (Barker and Härtel, 2004) while foreigners visiting China also report similar experiences coupled with poor service quality and low customer satisfaction (Tsang and Qu, 2000). However, both these countries are undergoing major cultural and socio-economic changes and greater engagement with each other, which makes them suitable for a study of intercultural 
service encounters. For example, both these countries are now major tourist destinations with 6.5 million inbound tourists in Australia and 20.8 million in China in 2014 (UNWTO, 2015). At the same time, the number of Chinese tourists visiting Australia has grown dramatically in ten years, from only 22,000 in 1993 to 715,000 in 2013 (ABS, 2013). Hence, it is important for services companies in both these countries to understand how culturally diverse domestic customers as well as overseas visitors evaluate their experience of dealing with local service employees.

Australia is becoming increasingly culturally diverse, with people born overseas (about 5.8 million) accounting for almost one-third (32\%) of 18.3 million people aged 15 years and above living in Australia in 2013 and about 10\% of these were born in China (ABS, 2013). As a result, many frontline jobs in Australia are now held by recent immigrants from non-English speaking countries, hence it is important to understand how Australian customers evaluate the quality of service provided by a culturally diverse workforce. In the meantime, Chinese economy is also growing rapidly, leading to an increase in both in-bound tourism as well as the number of foreigners living and working in China, which has soared by 35\% during 2000-2010 (Weiyun, 2014). Hence, it is important for service companies in China to understand how these culturally diverse customers evaluate their experience of dealing with local Chinese service employees. In addition, more than 45 million Chinese live overseas and many new immigrants to Australia, Europe and North America are highly educated, wealthy and socially mobile (China Daily, 2012), offering new opportunities for traditional services marketers in these developed countries.

\section{Sample and Procedure}

We used a 2 X 2 between-subjects lab experiment with 320 customers in Australia and China (160 each) with intercultural service encounter scenarios in a restaurant setting similar to 
the one used in prior research (e.g., Sharma, Tam, et al., 2012; Tam et al., 2014) to manipulate perceived cultural distance (low vs. high) and service outcome (success vs. failure). We pretested several versions of these scenarios and found the ones using a service recovery situation to be most effective in manipulating service failure and success. We recruited the participants using a mall-intercept approach and both the samples have similar characteristics in terms of gender ratio, age and employment profiles. Appendix I shows the different versions of the scenarios and Table 1 summarizes the sample characteristics.

\section{$<$ Insert Table 1 about here $>$}

We randomly assigned 40 participants each to one of the four conditions (i.e., low $\mathrm{PCD}$ /failure, low PCD/success, high PCD/failure, and high PCD/success) in both the countries. We used a structured questionnaire, which described an intercultural service encounter to manipulate the outcome (success or failure) and asked the participants to imagine being in that situation. We then showed photos of a Caucasian or a South-Asian waiter (chosen using a pretest) to manipulate perceived cultural distance followed by the manipulation checks and the remaining questions. We used both photos in a randomized manner to avoid any systematic bias and also collected demographic variables including age, gender, ethnicity and work experience (years).

We adapted well-established scales to measure all the constructs, including five-item scales for perceived cultural distance (Sharma, Tam, et al., 2012), independence, interdependence, risk aversion and ambiguity intolerance (Sharma, 2010), intercultural competence (Sharma, Tam, et al., 2012; Sharma and Zhan, 2015) and four-item consumer ethnocentrism scale (Sharma, 2011; Sharma and Zhan, 2015), all with a seven-point Likert response format. We also included three-item scales for interaction comfort (Spake et al., 2003) 
and perceived service quality (Sharma and Zhan, 2015; Zeithaml et al., 1996) and customer satisfaction (Brady et al., 2005; Seiders et al., 2005; Sharma and Zhan, 2015), all with a sevenpoint Semantic Differential format. We developed the questionnaire in English and translated it into Chinese using the back-translation (Brislin, 1970; Douglas and Craig, 2007) and pre-tested it in both the countries to ensure conceptual equivalence and no problems in comprehension.

\section{DATA ANALYSIS AND FINDINGS}

We used a two-step process to analyze our data (Anderson and Gerbing, 1988), by first testing our measurement model to assess the psychometric properties of all the scales using confirmatory factor analysis with AMOS 22. The measurement model shows a good fit $\left(\chi^{2}=\right.$ 1233.56, $\left.d f=826, \chi^{2} / d f=1.49, \mathrm{CFI}=.97, \mathrm{NFI}=.96, \mathrm{RMSEA}=.038, \mathrm{SRMR}=.044\right)$ with all the fit indices better than their cut-off values (CFI $>.95, \mathrm{NFI}>.90, \mathrm{RMSEA}<.06, \mathrm{SRMR}<.08,1 \leq$ $\left.\chi^{2} / d f \leq 3\right)$. All the factor loadings are higher than .60 with significant $t$-values $(p<.001)$ and no major cross-factor loadings $(>.40)$. Table 2 shows the properties of all the scales.

$<$ Insert Table 2 about here $>$

All the parameter estimates $(\lambda)$ are significantly different from zero at the $5 \%$ level showing convergent validity and none of the confidence intervals of the correlation coefficients for each pair of scales ( $\Phi$ estimates) includes 1.0 showing discriminant validity (Anderson and Gerbing, 1988). As an additional test of discriminant validity we constrained the estimated correlation parameters among all the factors to 1.0 and found the $\chi^{2}$ value for this constrained model $\left(\chi^{2}=1483.52, d f=892\right)$ significantly higher $\left(\Delta \chi^{2}=609.96, \Delta d f=66\right)$ than that for the unconstrained model, hence none of the factors are perfectly correlated with each other, providing further support for their discriminant validity (Anderson and Gerbing, 1988). All the 
scales are reliable with construct reliabilities $(.80$ to .92$)$ higher than.60, the recommended cutoff value (Bagozzi and Yi, 1988). Average variance extracted for each construct (.58 to .72) is also greater than .50 and higher than the square of its correlation with each of the other constructs, providing further evidence of convergent validity (Fornell and Larcker, 1981). Table 3 shows the correlations matrix for all the constructs with their composite reliabilities, average variance extracted and descriptives (mean and standard deviation).

$<$ Take in Table 3 about here $>$

Next, we checked the manipulations of perceived cultural distance and service outcome and found a significantly higher score $(\mathrm{F}=658.58, \mathrm{p}<.001)$ for the measured PCD variable under the high PCD condition $(M=5.91)$ compared to the low PCD condition $(M=3.02)$, and a significantly higher score $(\mathrm{F}=409.20, \mathrm{p}<.001)$ for customer satisfaction for the success outcome $(M=5.49)$ compared to the failure outcome $(M=2.76)$ condition. Hence, both these manipulations seem to have worked as expected.

\section{$<$ Take in Table 4 about here $>$}

We used hierarchical moderated multiple regression analysis to test all our hypotheses by first entering all our control variables with interaction comfort as the dependent variable (Model 1). As shown in Table 4, none of the control variables has any significant effect and they explain a negligible amount of variance in interaction comfort $\left(\mathrm{R}^{2}=.05, \mathrm{~F}=2.89, \mathrm{p}>.10\right)$. Next, we entered all the independent and moderator variables (Model 2) and it explains much higher variance in interaction comfort $\left(\mathrm{R}^{2}=.23, \mathrm{~F}=6.97, \mathrm{p}<.01\right)$ but with only $\mathrm{PCD}(\mathrm{H} 1: \beta=-.33, \mathrm{p}$ $<.001)$ and service outcome $(\mathrm{H} 2: \beta=.40, \mathrm{p}<.001)$ showing a significant effect on interaction comfort. We then entered the interaction terms of PCD and the four PCOs (Model 3) to test the 
moderating effects of the four PCOs on the influence of PCD on interaction comfort. Model 3 explains even more variance $\left(\mathrm{R}^{2}=.36, \mathrm{~F}=11.93, \mathrm{p}<.001\right)$ with three out of four personal cultural orientations and their interactions showing a significant effect on IC. Specifically, independence $(\mathrm{H} 3 \mathrm{a}: \beta=.19, \mathrm{p}<.01)$, risk aversion $(\mathrm{H} 5 \mathrm{a}: \beta=-.18, \mathrm{p}<.01)$ and ambiguity intolerance (H6a: $\beta=-.24, \mathrm{p}<0.01)$ as well as the interactions between PCD and independence (H3b: $\beta=-.29, \mathrm{p}<.001)$, risk aversion $(\mathrm{H} 5 \mathrm{~b}: \beta=.20, \mathrm{p}<.01)$ and ambiguity intolerance (H6b: $\beta$ $=.21, \mathrm{p}<0.01)$ have significant effects on interaction comfort. Hence, independence positively affect interaction comfort and it negatively moderates (weakens) the effect of PCD on interaction comfort; whereas risk aversion and ambiguity intolerance have a negative effect on interaction comfort and they positively moderate (strengthen) the effect of PCD on interaction comfort. However, the path coefficients for interdependence (H4a: $\beta=-.04, p>.10)$ and its interaction with PCD (H4b: $\beta=.08, p>.10)$ are not significant, hence interdependence does not seem to affect interaction comfort or moderate the influence of PCD on interaction comfort.

Next, we entered the interaction terms for service outcome with the four PCOs (Model 4) to test their moderating effects on the influence of service outcome on interaction comfort. Model 4 explains the maximum variance $\left(\mathrm{R}^{2}=.43, \mathrm{~F}=14.82, \mathrm{p}<.001\right)$ among all the models, with all four personal cultural orientations and three out of the four interactions showing a significant effect on interaction comfort. Specifically, independence $(\mathrm{H} 3 \mathrm{a}: \beta=.31, \mathrm{p}<.001)$, interdependence (H4a: $\beta=-.12, p<.05)$, risk aversion $(\mathrm{H} 5 \mathrm{a}: \beta=-.23, \mathrm{p}<.01)$ and ambiguity intolerance (H5c: $\beta=-.20, \mathrm{p}<0.01)$ as well as the interactions between outcome and independence $(\mathrm{H} 3 \mathrm{c}: \beta=.18, \mathrm{p}<.01)$, risk aversion $(\mathrm{H} 5 \mathrm{c}: \beta=-.22, \mathrm{p}<.01)$ and ambiguity intolerance (H6c: $\beta=-.19, \mathrm{p}<0.01)$ have significant effects on interaction comfort, showing support for all these hypotheses. Specifically, independence has a positive effect on interaction 
comfort and it also moderates (strengthens) the effect of outcome on interaction comfort; whereas interdependence, risk aversion and ambiguity intolerance negatively affect interaction comfort and also negatively moderate (weaken) the effect of outcome on interaction comfort. However, the interaction between outcome and interdependence is not significant (H4c: $\beta=-.04$, $\mathrm{p}>.10$ ); hence, interdependence does not moderate the influence of outcome on interaction comfort. In other words, there is no significant difference in the interaction comfort between service failure and success for the participant with higher levels of interdependence.

Finally, we tested our remaining hypotheses using two separate multiple regression model with perceived service quality and customer satisfaction as the dependent variables respectively and all the independent variables and their interaction terms along with interaction comfort as the predictors. Both the models show good fit $\left(\mathrm{PSQ}: \mathrm{R}^{2}=.45, \mathrm{~F}=17.38, \mathrm{p}<.001\right)$ and $\left(\mathrm{SAT}: \mathrm{R}^{2}=.48, \mathrm{~F}=18.44, \mathrm{p}<.001\right)$. As expected, interaction comfort has a significant positive effect on both perceived service quality $(\mathrm{H} 7: \beta=.34, \mathrm{p}<.001)$ and customer satisfaction $(\mathrm{H} 8: \beta=.28, \mathrm{p}<.001)$, and perceived service quality has a positive effect on customer satisfaction $(\mathrm{H} 9: \beta=.42, \mathrm{p}<.001)$. Thus, all these hypotheses are supported.

\section{DISCUSSION}

\section{Conceptual Contribution}

This paper addresses three specific research gaps and contributes to the growing literature on intercultural service encounter. First, we introduce a new conceptual framework (Figure 1) incorporating four personal cultural orientations as the moderators of the influence of perceived cultural distance and service outcome on interaction comfort, which in turn affects perceived service quality and customer satisfaction. We look beyond consumer ethnocentrism and 
intercultural competence (Sharma and Zhan, 2015), to directly investigate the role of culture in intercultural service encounters, which may help explain some of the mixed and inconclusive findings about the influence of perceived cultural distance. Second, we study the influence of culture resulting in both failure and success, to seek deeper insights into customer expectations, perceptions and evaluations in intercultural service encounters. Third, we use personal cultural orientations (Sharma 2010) rather than national cultural dimensions (Hofstede 1980, 1991, 2001) because of concerns raised about the use of Hofstede's framework to operationalize culture at individual level. Thus, our paper is one of the first efforts to explore the influence of personal cultural orientations on customer and employee perceptions and evaluations in intercultural service encounters and pave the way for more research in this area of growing importance.

We demonstrate that in addition to the main effects of variables such as PCD and service outcome, it is critical to examine the variables which might moderate their influence on important outcome variables such as interaction comfort, perceived service quality and customer satisfaction. To the best of our knowledge this is the first evidence about both direct and indirect effects of personal cultural orientations in intercultural service encounters. We used an experimental approach similar to prior research (Sharma, Tam, et al., 2012; Sharma et al., 2015; Sharma and Zhan, 2015) as it provides a good control on the various external factors that could confound other methods such as critical incidence technique and field surveys. We also control for various demographic variables as well as other relevant constructs such as consumer ethnocentrism and intercultural competence used in past research (Sharma and Zhan, 2015).

We found support for all our hypotheses except two (H4a and H4b). First, as expected both PCD (H1) and service failure (H2) have negative effects on interaction comfort but more importantly, all the four personal cultural orientations also have a direct effect on interaction 
comfort. Specifically, we show that independent people, who value personal freedom and tend to rely on themselves most of the time, may experience greater interaction comfort in intercultural service encounters (H3a), possibly because they are more tolerant towards culturally distant service employees and are not influenced by the stereotypes about people from other cultures. We also found a negative direct effect of interdependence on interaction comfort (H4a) showing that people who favor and depend more on in-groups than out-groups, may find it uncomfortable to deal with service employees from other cultures because they are perceived as members of out-groups. We also found that high risk-averse (H5a) and ambiguity intolerant (H6a) customers experience more discomfort in intercultural service encounters possibly because they may find dealing with culturally distant service employees quite difficult, risky and uncomfortable.

In addition to these direct effects of PCOs, we also found that three of these PCOs (i.e., independence, risk aversion and ambiguity intolerance) also moderate the impact of PCD and service outcome on interaction comfort. Specifically, the negative effects of PCD and service failure on interaction comfort are stronger for customers with lower levels of independence (H3b \& H3c) and higher levels of risk aversion (H5b \& H5c) and ambiguity intolerance (H6b \& H6c). However, we did not find support for the moderating effect of interdependence on the effects of PCD (H4b) and outcome ( $\mathrm{H} 4 \mathrm{c})$ on interaction comfort, possibly because our sample is relatively younger than the actual population in both the countries (Australia and China) in our study and the young participants in our Chinese sample may be less influenced by their interdependent values than their older counterparts. In fact, similar results are reported by other researchers about the changing cultural values in China and their impact on young Chinese customers' attitudes and purchase behavior (e.g., Hung, Gu and Yim, 2007; Xiao and Kim, 2009). 
Recent research explores the moderating roles of consumer ethnocentrism and intercultural competence in intercultural service encounters (Sharma and Zhan, 2015) showing that both these variables have contrasting moderating effects on the impact of perceived cultural distance and service outcome on interaction comfort and customer satisfaction. Therefore, we included both these two along with many demographic characteristics (e.g., age, gender, income and work experience) as control variables. However, we found that all these control variables explain only about $5 \%$ variance in interaction comfort, whereas PCD, service outcome, the four cultural variables and their interactions explain an additional $38 \%$ variance. Thus, our new conceptual framework provides additional insights into the complex socio-psychological process underlying customers' evaluation of intercultural service encounters and highlights the importance of looking beyond consumer ethnocentrism and intercultural competence.

\section{Managerial Implications}

This paper also has some important managerial insights and implications. First, we show that in addition to the direct effects of PCD and service outcome on customer expectations, perceptions and evaluations, services marketers need to understand the impact of personal cultural orientations in intercultural service encounters. For example, prior research shows that customers with higher scores on independence (or, individualism) may seem to be more demanding and vocal compared to those with higher scores on interdependence (or, collectivism) (Donthu and Yoo, 1998; Furrer et al., 2000; Mattila, 1999), however we found that independent customers are also more tolerant and likely to accept cultural differences in intercultural service encounters even in service failures, compared to interdependent customers. Therefore, service firms dealing with independent customers should train their frontline employees to ensure that they provide at least the adequate service level without worrying about the cultural differences. 
Second, in line with prior research showing that customers with high interdependence, risk aversion and ambiguity intolerance generally have high expectations and narrower zones of tolerance (Mattila, 1999; Mattila and Patterson, 2004a; Reimann et al., 2008), we found that such customers also feel more uncomfortable with culturally distant service employees and in service failures. Therefore, service companies dealing with such customers need to take special care in identifying and training frontline service employees who are aware of such negative perceptions of their culturally distant customers (e.g., offshore call center companies in India and Philippines with their customers in Australia or United States) in order to serve them better. All these findings are especially important for services marketers in the emerging markets (e.g., China, India, Brazil and Russia) because these have large number of customers with interdependence as their primary cultural orientation and hence it is important for services marketers to understand how these customers would perceive and evaluate their experience in intercultural service encounters with culturally distant employees due to growing globalization and migration.

Overall, our findings highlight the importance of looking beyond perceived cultural distance as reflected in visible cultural differences such as ethnicity, nationality and language, and focusing more on the invisible cultural differences in customs, values and norms, as reflected by the personal cultural orientations (Sharma 2010). In this regard, service firms should guard against using national cultural scores as indicators of their individual customers' cultural orientation because there is now sufficient evidence that not all people in a society or nation share the same cultural values. However, it is not easy for service firms to know how their individual customers rank on each personal cultural orientation; hence they would need to integrate measures of cultural factors into their customer relationship management (CRM) 
systems in order to capture this data as a part of customer profiles in their CRM databases, at the time of signing up the customers or at various touch-points during the customer's life-cycle.

\section{LIMITATIONS AND FUTURE RESEARCH}

Our research has a few limitations that future research may address. First, we collected our data in two countries (Australia and China) that represent significantly different cultural values as well as stages of socio-economic development but for greater generalizability, it would be useful to conduct studies in other countries with a wider range of economic development and cultural orientations. Second, we focus on four personal cultural orientations (Sharma 2010) as moderators for parsimony but future research may use other cultural factors such as social inequality and gender equality (Sharma 2010), power distance and masculinity/femininity (Hofstede, 1991), competence (Bond, 1988), achievement (Trompenaars, 1993), self-direction (Schwartz, 1994), autonomy (Steenkamp, 2001) and ethnic stereotypes (Hilton and Von Hippel, 1996). Third, we only use customers' perspective in this study to keep our model parsimonious but it would be useful to explore the differences and similarities between the customers and employees with more complex models. Fourth, we used a scenario-based lab experiment in this study, to ensure greater control over possible confounding factors but this may limit the generalizability of our findings; hence, future research may use other methods (e.g., field experiments) that are closer to the real-life experiences of customers, with different types of services and nature of service encounters. Finally, our sample is relatively young, includes only two ethnicities (Chinese and Caucasian) and does not account for multiple cultural identities; hence future research with a more diverse sample (older, different ethnicities and bi- or multicultural identities) would help further validate and test the generalizability of our results. 


\section{REFERENCES}

ABS (2013), Characteristics of Recent Migrants, Australia [Online]. Australian Bureau of Statistics. Available: http://www.abs.gov.au/ausstats/abs@.nsf/PrimaryMainFeatures/6250.0.

Albers-Miller, N. and Gelb, B. (1996), "Business advertising appeals as a mirror of cultural dimensions: a study of eleven countries", Journal of Advertising, Vol. XXV No. 4, pp. $57-70$.

Ali-Sulaiti, K.I. and Baker, M.J. (1998), "Country of origin effects: a literature review", Marketing Intelligence \& Planning, Vol. 16 No. 3, pp. 150-199.

Anderson, J.C. and Gerbing, D.W. (1988), "Structural equation modeling in practice: A review and recommended two step approach", Psychological Bulletin, Vol. 103 No. May, pp. 411-423.

Bagozzi, R.P. and Yi, Y. (1988), "On the evaluation of structural equation models", Journal of the Academy of Marketing Sciences, Vol. 16 No. 1, pp. 74- 84.

Barker, S. and Härtel, C.E.J. (2004), "Intercultural Service Encounters: An Exploratory Study of Customer Experiences", Cross Cultural Management, Vol. 11 No. 1, pp. 3-14.

Berry, J.W. (1974), "Psychological aspects of cultural pluralism", Topics in Culture Learning, Vol. 2 No., pp. 17-22.

Berry, J.W. (2005), "Acculturation: Living successfully in two cultures", International Journal of Intercultural Relations, Vol. 29 No., pp. 697-712.

Birgelen, M.V., de Ruyter, K., Jeong, A.d. and Wetzels, M. (2002), "Customer evaluations of after-sales service contact modes: an empirical analysis of national culture's consequences", International Journal of Research in Marketing, Vol. 19 No. 1, pp. 43-64.

Bond, M.H. (1988), "Finding universal dimensions of individual variation in multi-cultural studies of values: The Rokeach and Chinese value surveys", Journal of Personality and Social Psychology, Vol. 55 No. 6, pp. 1009-1015.

Bontempo, R.N., Bottom, W.P. and Weber, E.U. (1997), "Cross-cultural Differences in Risk Perception: A Model-based Approach", Risk Analysis, Vol. 17 No. 4, pp. 479-488.

Brady, M.K., Knight, G.A., Cronin, J.J.J., Hult, G.T.M. and Keillor, B.D. (2005), "Removing the Contextual Lens: A Multinational, Multi-Setting Comparison of Service Evaluation Models", Journal of Retailing, Vol. 81 No. 3, pp. 215-230.

Brislin, R.W. (1970), "Back-Translation for Cross-Cultural Research", Journal of Cross-Cultural Psychology, Vol. 1 No. 3, pp. 185-216. 
China Daily (2012), Overseas Chinese Distribution [Online]. China Daily. Available: http://cbl.chinadaily.com.cn/2012-09/06/content 15739384.htm.

Chuapetcharasopon, P. (2014), Emotional Labour in the Global Context: The Roles of Intercultural and Intracultural Service Encounters, Intergroup Anxiety, and Cultural Intelligence on Surface Acting. University of Waterloo.

Crotts, J.C. and Erdmann, R. (2000), "Does national culture influence consumers' evaluation of travel services? A test of Hofstede's model of cross-cultural differences", Managing Service Quality, Vol. 10 No. 6, pp. 410-419.

de Mooij, M.K. and Hofstede, G. (2002), "Convergence and Divergence in Consumer behavior: Implications for International Retailing", Journal of Retailing, Vol. 78 No. 1, pp. 61-69.

Demangeot, C., Broderick, A.J. and Craig, C.S. (2015), "Multicultural marketplaces: New territory for international marketing and consumer research", International Marketing Review, Vol. 32 No. 2, pp. 118-140.

Dolen, W.v., Ruyter, K.d. and Lemmink, J. (2004), "An empirical assessment of the influence of customer emotions and contact employee performance on encounter and relationship satisfaction", Journal of Business Research, Vol. 57 No. 4, pp. 437-444.

Donthu, N. and Yoo, B. (1998), "Cultural influences on service quality expectations", Journal of Service Research, Vol. 1 No. 2, pp. 178-186.

Dorfman, P. and Howell, J. (1988), Dimensions of National Culture and Effective Leadership Patterns: Hofstede Revisited. In: Farmer, R.N. and McGoun, E.G. (eds.) Advances in International Comparative Management. New York: JAI Press, pp. 127-150.

Douglas, S.P. and Craig, C.S. (1997), "The Changing Dynamic of Consumer Behavior: Implications for Cross-Cultural Research", International Journal of Research in Marketing, Vol. 14 No. 4, pp. 379-395.

Douglas, S.P. and Craig, C.S. (2007), "Collaborative and iterative translation: an alternative approach to back translation", Journal of International Marketing, Vol. 15 No. 1, pp. 3043.

Erdem, T., Swait, J. and Valenzuela, A. (2006), "Brands as Signals: A Cross-Country Validation Study", Journal of Marketing, Vol. 70 No. 1, pp. 34-49.

Etgar, M. and Fuchs, G. (2011), "Does Ethnic/Cultural Dissimilarity Affect Perceptions of Service Quality?", Services Marketing Quarterly, Vol. 32 No. 2, pp. 113-128.

Fornell, C. and Larcker, D.F. (1981), "Evaluating Structural Equation Models with Unobservable Variables and Measurement Error", Journal of Marketing Research, Vol. 18 No. 1, pp. 39-50. 
Furrer, O., Liu, B.S.-C. and Sudharshan, D. (2000), "The Relationships Between Culture and Service Quality Perceptions: Basis for Cross-cultural Market Segmentation and Resource Allocation", Journal of Service Research, Vol. 2 No. 4, pp. 355-371.

Grenier, S., Barrette, A.-M. and Ladouceur, R. (2005), "Intolerance of uncertainty and intolerance of ambiguity: Similarities and differences", Personality and individual differences, Vol. 39 No. 3, pp. 593-600.

Harrison-Walker, L.J. (1995), "The relative effects of national stereotype and advertising information on the selection of a service provider", Journal of Services Marketing, Vol. 9 No. 1, pp. 47-59.

Hilton, J.L. and Von Hippel, W. (1996), "Stereotypes", Annual review of psychology, Vol. 47 No. 1, pp. 237-271.

Hofstede, G. (1980), Culture's Consequences: International Differences in Work-related Values, ed., Sage Publications, Beverly Hills, CA.

Hofstede, G. (1991), Cultures and Organizations: Software of the Mind ed., McGraw-Hill, London, UK.

Hofstede, G. (2001), Culture's consequences: comparing values, behaviors, institutions, and organizations across nations, 2nd ed., Sage Publications, Thousand Oaks, CA.

Hofstede, G. and Bond, M.H. (1988), "The Confucius Connection: From Cultural Roots to Economic Growth", Organizational Dynamics, Vol. 16 No. Spring, pp. 5-21.

Hofstede, G., Hofstede, G.J. and Minkov, M. (2010), Cultures and Organizations: Software of the Mind, 3rd ed., McGraw-Hill, New York, NY.

Hong, Y.-y., Morris, M.W., Chiu, C.-y. and Benet-Martínez, V. (2000), "Multicultural Minds: A Dynamic Constructivist Approach to Culture and Cognition", American Psychologist, Vol. 55 No. Aug, pp. 709-720.

Hopkins, S.A., Hopkins, W.E. and Hoffman, K.D. (2005), "Domestic inter-cultural service encounters: an integrated model", Managing Service Quality, Vol. 15 No. 4, pp. 329-343.

Hui, C.H. (1988), "Measurement of individualism-collectivism", Journal of Research in Personality, Vol. 22 No., pp. 17-36.

Hung, K.H., Gu, F.F. and Yim, C.K.B. (2007), "A social institutional approach to identifying generation cohorts in China with a comparison with American consumers", Journal of International Business Studies, Vol. 38 No. 5, pp. 836-853.

Jung, J.M. and Kellaris, J.J. (2006), "Responsiveness to authority appeals among young French and American consumers", Journal of Business Research, Vol. 59 No., pp. 735-744. 
Keh, H.T. and Sun, J. (2008), "The Complexities of Perceived Risk in Cross-Cultural Services Marketing", Journal of International Marketing, Vol. 16 No. 1, pp. 120-146.

Kueh, K. and Voon, B.H. (2007), "Culture and service quality expectations: Evidence from Generation Y consumers in Malaysia", Managing Service Quality: An International Journal, Vol. 17 No. 6, pp. 656-680.

Kulik, C.T. and Holbrook, R.L.J. (2000), "Demographics in Service Encounters: Effects of Racial and Gender Congruence on Perceived Fairness", Social Justice Research, Vol. 13 No. 4, pp. 375-402.

Laroche, M., Ueltschy, L.C., Abe, S., Cleveland, M. and Yannopoulos, P.P. (2004), "Service Quality Perceptions and Customer Satisfaction: Evaluating the Role of Culture", Journal of International Marketing, Vol. 12 No. 3, pp. 58-85.

Lau, I., Chiu, C.-y. and Lee, S.-1. (2001), "Communication and Shared Reality: Implications for the Psychological Foundations of Culture", Social Cognition, Vol. 19 No. June, pp. 350371.

Laufer, D. (2002), "Are Antecedents of Consumer Dissatisfaction and Consumer Attributions for Product Failures Universal?". In: Broniarczyk, S.M. and Nakamoto, K., eds. Advances in Consumer Research, Valdosta, GA. Association for Consumer Research, pp. 312-317.

Lee, Y.H. and Lim, E.A.C. (2008), "What's Funny and What's not: The Moderating Role of Cultural Orientation in Ad Humor", Journal of Advertising, Vol. 37 No. 2, pp. 71-83.

Leong, C.-H. and Ward, C. (2000), "Identity conflict in sojourners", International Journal of Intercultural Relations, Vol. 24 No. 6, pp. 763-776.

Liu, B.S.-c., Furrer, O. and Sudharshan, D. (2001), "The Relationships between Culture and Behavioral Intentions toward Services", Journal Of Service Research, Vol. 4 No. 2, pp. 118-129.

Markus, H.R. and Kitayama, S. (1991), "Culture and The Self: Implications for Cognition, Emotion and Motivation", Psychological Bulletin, Vol. 98 No. 2, pp. 224-253.

Mattila, A.S. (1999), "The Role of Culture in the Service Evaluation Process", Journal of Service Research, Vol. 1 No. 3, pp. 250-261.

Mattila, A.S. and Patterson, P.G. (2004a), "The Impact of Culture on Consumers' Perceptions of Service Recovery Efforts", Journal of Retailing, Vol. 80 No. 3, pp. 196-206.

Mattila, A.S. and Patterson, P.G. (2004b), "Service Recovery and Fairness Perceptions in Collectivist and Individualist Contexts", Journal of Service Research, Vol. 6 No. 4, pp. 336-346.

Minkov, M. and Hofstede, G. (2010), "Hofstede's fifth dimension: new evidence from the World Values Survey", Journal of Cross-Cultural Psychology, Vol. 43 No. 1, pp. 3-14. 
Mohr, L.A. and Bitner, M.J. (1995), "The Role of Employee Effort in Satisfaction with Service Transactions", Journal of Business Research, Vol. 32 No., pp. 239-252.

Oliver, R.L. (1997), Satisfaction: A Behavioral Perspective on the Consumer, ed., McGraw-Hill, New York, NY.

Oliver, R.L., Rust, R.T. and Varki, S. (1997), "Customer delight: Foundations, findings, and managerial insight", Journal of Retailing, Vol. 73 No. 3, pp. 311-336.

Oyserman, D., Coon, H.M. and Kemmelmeier, M. (2002), "Rethinking individualism and collectivism: Evaluation of theoretical assumptions and meta-analyses", Psychological Bulletin, Vol. 128 No. 1, pp. 3-72.

Oyserman, D., Kemmelmeier, M. and Coon, H.M. (2002), "Cultural psychology, a new look: Reply to Bond (2002), Fiske (2002), Kitayama (2002), and Miller", Psychological Bulletin, Vol. 128 No. 1, pp. 110-117.

Parasuraman, A., Zeithaml, V.A. and Berry, L.L. (1988), "SERVQUAL: A multiple-item scale for measuring consumer perceptions of service quality", Journal of Retailing, Vol. 64 No. 1, pp. 12-37.

Paswan, A.K. and Ganesh, G. (2005), "Cross-Cultural Interaction Comfort and Service Evaluation", Journal of International Consumer Marketing, Vol. 18 No. 1/2, pp. 93-115.

Pecotich, A. and Rosenthal, M.J. (2001), "Country of origin, quality, brand and consumer ethnocentrism", Journal of Global Marketing, Vol. 15 No. 2, pp. 31-60.

Reimann, M., Lünemann, U.F. and Chase, R.B. (2008), "Uncertainty Avoidance as a Moderator of the Relationship between Perceived Service Quality and Customer Satisfaction", Journal of Service Research, Vol. 11 No. 1, pp. 63-73.

Schneider, B. and Bowen, D.E. (1985), "Employee and customer perceptions of service in banks: Replication and extension", Journal of Applied Psychology, Vol. 70 No. 3, pp. 423-433.

Schwartz, S.H. (1994), Beyond individualism/collectivism: New cultural dimensions of values. In: Kim, U., Triandis, H.C., Kagitcibasi, C., Choi, S. and Yoon, G. (eds.) Individualism and collectivism: Theory, method, and applications. Thousand Oaks, CA: Sage, pp. 85119.

Schwartz, S.H., Melech, G., Lehmann, A., Burgess, S., Harris, M. and Owens, V. (2001), "Extending the Cross-Cultural Validity of the Theory of Basic Human Values with a Different Method of Measurement", Journal of Cross-Cultural Psychology, Vol. 32 No. 5, pp. 519-542.

Seiders, K., Voss, G.B., Grewal, D. and Godfrey, A.L. (2005), "Do Satisfied Customers Buy More? Examining Moderating Influences in a Retailing Context", Journal of Marketing, Vol. 69 No. October, pp. 26-43. 
Sharma, P. (2010), "Measuring Personal Cultural Orientations: Scale Development and Validation", Journal of the Academy of Marketing Science, Vol. 38 No. 6, pp. 787-806.

Sharma, P. (2011), "Country-of-Origin Effects in Developed vs. Emerging Markets: Exploring the Contrasting Roles of Materialism and Value-Consciousness", Journal of International Business Studies, Vol. 42 No. 2, pp. 285-306.

Sharma, P., Chen, I.S.N. and Luk, S.T.K. (2012), "Exploring the Role of IND-COL as a Moderator in the Comprehensive Service Evaluation Model", Journal of International Consumer Marketing, Vol. 24 No. 1-2, pp. 129-142.

Sharma, P., Tam, J.L.M. and Kim, N. (2009), "Demystifying Intercultural Service Encounters: Toward a Comprehensive Conceptual Framework", Journal of Service Research, Vol. 12 No. 2, pp. 227-242.

Sharma, P., Tam, J.L.M. and Kim, N. (2012), "Intercultural Service Encounters (ICSE) Framework: Extension and Empirical Validation", Journal of Services Marketing, Vol. 26 No. 7, pp. 521-534.

Sharma, P., Tam, J.L.M. and Kim, N. (2015), "Service Role and Outcome as Moderators in Intercultural Service Encounters", Journal of Service Management, Vol. 26 No. 1, pp. 137-155.

Sharma, P. and Zhan, W. (2015), "Consumer Ethnocentrism vs. Intercultural Competence as Moderators in Intercultural Service Encounters", Journal of Services Marketing, Vol. 29 No. 2, pp. 93-102.

Sivakumar, K. and Nakata, C. (2001), "The Stampede Toward Hofstede's Framework: Avoiding the Sample Design Pit in Cross-Cultural Research", Journal of International Business Studies, Vol. 32 No. 3, pp. 555-573.

Smith, P.B., Dugan, S. and Trompenaars, F. (1996), "National culture and the values of organizational employees: A dimensional analysis across 43 nations", Journal of CrossCultural Psychology, Vol. 27 No. 2, pp. 231-264.

Spake, D.F., Beatty, S.E., Brockman, B.K. and Crutchfield, T.N. (2003), "Consumer Comfort in Service Relationships: Measurement and Importance", Journal of Service Research, Vol. 5 No. 4, pp. 316-332.

Stauss, B. and Mang, P. (1999), "'Culture Shocks" in Inter-cultural Service Encounters?", Journal of Services Marketing, Vol. 13 No. 4/5, pp. 329-346.

Steenkamp, J.-B.E.M. (2001), "The role of national culture in international marketing research", International Marketing Review, Vol. 18 No. 1, pp. 30-44.

Steenkamp, J.-B.E.M., Hofstede, F.t. and Wedel, M. (1999), "A Cross-National Investigation into the Individual and National Cultural Antecedents of Consumer Innovativeness", Journal of Marketing, Vol. 63 No. April, pp. 55-69. 
Stening, B.W. (1979), "Problems in cross-cultural contact: A literature review", International Journal of Intercultural Relations, Vol. 3 No. 3, pp. 269-313.

Tam, J.L.M., Sharma, P. and Kim, N. (2014), "Examining the Role of Attribution and Intercultural Competence in Intercultural Service Encounters", Journal of Services Marketing, Vol. 28 No. 2, pp. 159-170.

Teng, C.-C. (2011), "Commercial hospitality in restaurants and tourist accommodation: Perspectives from international consumer experience in Scotland", International Journal of Hospitality Management, Vol. 30 No. 4, pp. 866-874.

Triandis, H.C. (1999), "Cross-cultural Psychology", Asian Journal Of Social Psychology, Vol. 2 No. 1, pp. 127-143.

Trompenaars, F. (1993), Riding the Waves of Culture, ed., The Economists Books, London, UK.

Tsang, N. and Qu, H. (2000), "Service quality in China's hotel industry: a perspective from tourists and hotel managers", International Journal of Contemporary Hospitality Management, Vol. 12 No. 5, pp. 316-326.

Tsoukatos, E. and Rand, G.K. (2007), "Cultural influences on service quality and customer satisfaction: evidence from Greek insurance", Managing Service Quality: An International Journal, Vol. 17 No. 4, pp. 467-485.

Ueltschy, L.C., Laroche, M., Eggert, A. and Bindl, U. (2007), "Service quality and satisfaction: an international comparison of professional services perceptions", Journal of Services Marketing, Vol. 21 No. 6, pp. 410-423.

UNWTO (2015), Inbound Tourist Arrivals. World Tourism Barometer. Madrid, Spain: World Tourism Organization, pp. 1-7.

Wang, C.-y. and Mattila, A.S. (2010), "A grounded theory model of service providers' stress, emotion, and coping during intercultural service encounters", Managing Service Quality, Vol. 20 No. 4, pp. 328-342.

Wang, C.-y. and Mattila, A.S. (2011), "A cross-cultural comparison of perceived informational fairness with service failure explanations", Journal of Services Marketing, Vol. 25 No. 6, pp. 429-439.

Wang, C.L. and Chen, Z.X. (2004), "Consumer ethnocentrism and willingness to buy domestic products in a developing country setting: testing moderating effects", Journal of Consumer Marketing, Vol. 21 No. 6, pp. 391-400.

Ward, C. (2008), "Thinking outside the Berry boxes: New perspectives on identity, acculturation and intercultural relations", International Journal of Intercultural Relations, Vol. 32 No., pp. 105-114. 
Ward, C. and Kennedy, A. (2001), "Coping with Cross-Cultural Transition", Journal of CrossCultural Psychology, Vol. 32 No. 5, pp. 636 - 642.

Ward, C. and Rana-Deuba, A. (2000), "Home and host culture influences on sojourner adjustment", International Journal of Intercultural Relations, Vol. 24 No. 3, pp. 291-306.

Warden, C.A., Liu, T.-C. and Huang, C.-T. (2003), "Service Failures Away from Home: Benefits in Intercultural Service Encounters", International Journal of Service Industry Management, Vol. 14 No. 4, pp. 436-457.

Weiermair, K. (2000), "Tourists' perceptions towards and satisfaction with service quality in the cross-cultural service encounter: implications for hospitality and tourism management", Managing Service Quality, Vol. 10 No. 6, pp. 397-409.

Weiyun, T. (2014), More foreigners coming to live in China [Online]. Shanghai Daily. Available: http://english.people.com.cn/n/2014/0602/c90882-8735618.html.

Xiao, G. and Kim, J.-O. (2009), "The investigation of Chinese consumer values, consumption values, life satisfaction, and consumption behaviors", Psychology and Marketing, Vol. 26 No. 7, pp. 610-624.

Yoo, B. and Donthu, N. (2005), "The effect of personal cultural orientation on consumer ethnocentrism: Evaluations and behaviors of U.S. consumers toward Japanese products", Journal of International Consumer Marketing, Vol. 18 No. 1-2, pp. 7-44.

Yoo, B., Donthu, N. and Lenartowicz, T. (2011), "Measuring Hofstede's Five Dimensions of Cultural Values at the Individual Level: Development and Validation of CVSCALE", Journal of International Consumer Marketing, Vol. 23 No. 3-4, pp. 193-210.

Zeithaml, V.A., Berry, L.L. and Parasuraman, A. (1996), "The behavioral consequences of service quality", Journal of Marketing, Vol. 60 No. 2, pp. 31-46. 
Figure 1 - Conceptual framework

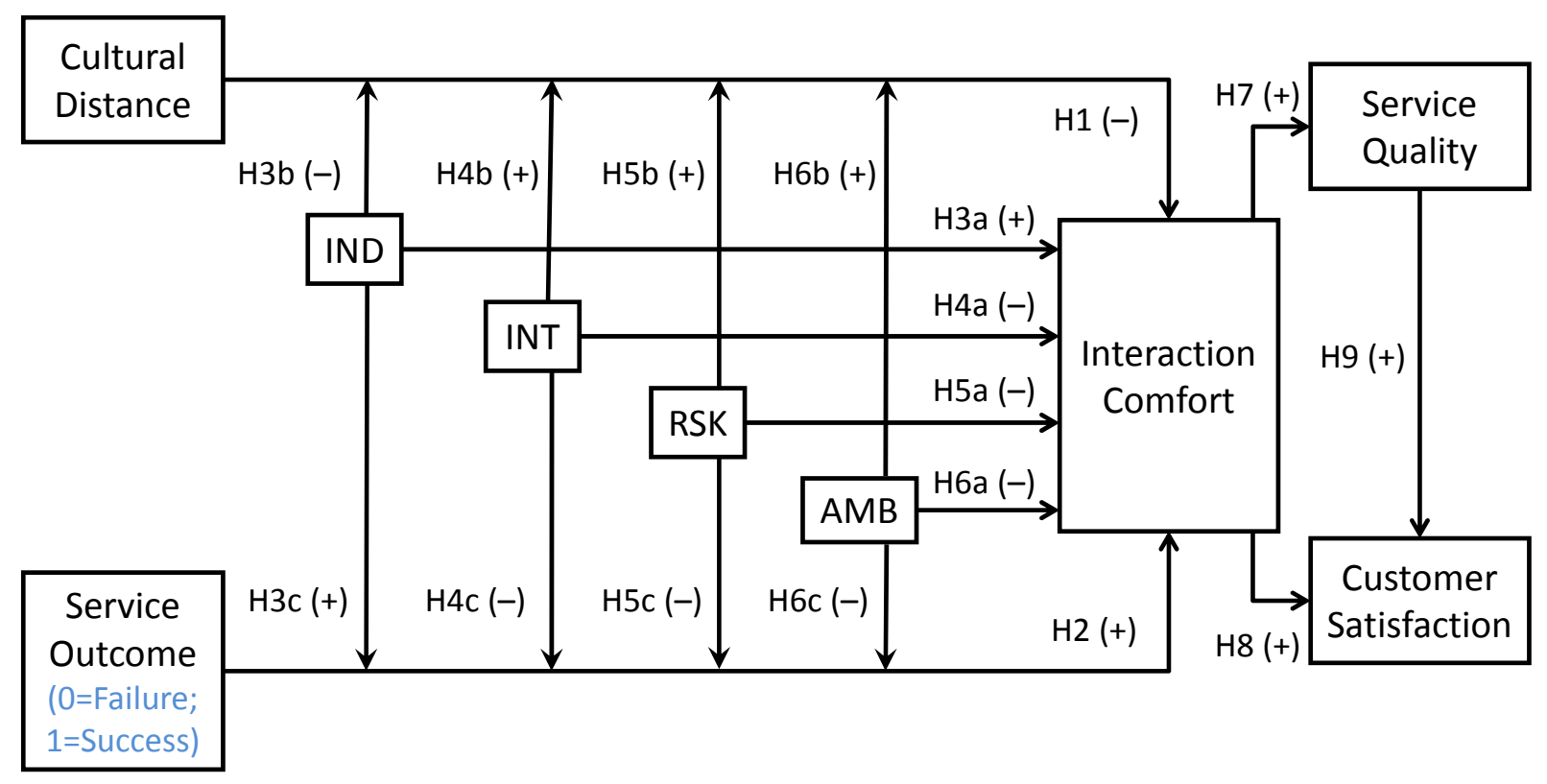


Table 1 - Sample Profile $(\mathbf{N}=320)$

\begin{tabular}{|c|c|c|c|c|c|c|c|}
\hline \multirow{2}{*}{ Demographics } & \multicolumn{2}{|c|}{$\begin{array}{c}\text { Low PCD } \\
(N=160)\end{array}$} & \multicolumn{2}{|c|}{$\begin{array}{c}\text { High PCD } \\
(\mathbf{N}=160)\end{array}$} & \multicolumn{3}{|c|}{ Overall $(\mathrm{N}=320)$} \\
\hline & $\begin{array}{l}\text { Failure } \\
(N=80)\end{array}$ & $\begin{array}{c}\text { Success } \\
(\mathrm{N}=\mathbf{8 0})\end{array}$ & $\begin{array}{l}\text { Failure } \\
(\mathrm{N}=\mathbf{8 0})\end{array}$ & $\begin{array}{l}\text { Failure } \\
(\mathrm{N}=\mathbf{8 0})\end{array}$ & $\begin{array}{c}\text { Australia } \\
(N=160)\end{array}$ & $\begin{array}{c}\text { China } \\
(\mathrm{N}=160)\end{array}$ & $\begin{array}{c}\text { Total } \\
(\mathbf{N}=320)\end{array}$ \\
\hline \multicolumn{8}{|l|}{ Gender } \\
\hline Female & $44(55 \%)$ & $43(54 \%)$ & $45(56 \%)$ & $42(52 \%)$ & $89(56 \%)$ & $85(53 \%)$ & $174(54 \%)$ \\
\hline Male & $36(45 \%)$ & $37(46 \%)$ & $35(44 \%)$ & $38(48 \%)$ & $71(44 \%)$ & $75(47 \%)$ & $146(46 \%)$ \\
\hline \multicolumn{8}{|l|}{ Age } \\
\hline$\leq 20$ & $9(11 \%)$ & $13(16 \%)$ & $12(15 \%)$ & $8(10 \%)$ & $19(12 \%)$ & $23(14 \%)$ & $42(13 \%)$ \\
\hline $21-30$ & $25(31 \%)$ & $24(30 \%)$ & $22(28 \%)$ & $27(34 \%)$ & $48(30 \%)$ & $50(31 \%)$ & $98(31 \%)$ \\
\hline $31-40$ & $21(26 \%)$ & $19(24 \%)$ & $21(26 \%)$ & $20(25 \%)$ & $44(28 \%)$ & $37(23 \%)$ & $81(25 \%)$ \\
\hline $41-50$ & $16(21 \%)$ & $18(23 \%)$ & $17(21 \%)$ & $20(25 \%)$ & $36(23 \%)$ & $35(22 \%)$ & $71(22 \%)$ \\
\hline$>50$ & $9(11 \%)$ & $6(7 \%)$ & $8(10 \%)$ & $5(6 \%)$ & $13(8 \%)$ & $15(9 \%)$ & $28(9 \%)$ \\
\hline \multicolumn{8}{|l|}{ Ethnicity } \\
\hline Chinese & $38(48 \%)$ & $42(52 \%)$ & $39(49 \%)$ & $44(55 \%)$ & $16(10 \%)$ & $147(92 \%)$ & $163(51 \%)$ \\
\hline Caucasian & $42(52 \%)$ & $38(48 \%)$ & $41(51 \%)$ & $36(45 \%)$ & $144(90 \%)$ & $13(8 \%)$ & $157(49 \%)$ \\
\hline \multicolumn{8}{|c|}{ Work Experience } \\
\hline$<=2$ years & $6(7 \%)$ & $13(16 \%)$ & $9(11 \%)$ & $12(15 \%)$ & $19(12 \%)$ & $21(13 \%)$ & $40(13 \%)$ \\
\hline $3-4$ years & $20(25 \%)$ & $15(19 \%)$ & $21(26 \%)$ & $20(25 \%)$ & $33(21 \%)$ & $43(27 \%)$ & $76(24 \%)$ \\
\hline $5-6$ years & $18(23 \%)$ & $19(24 \%)$ & $17(21 \%)$ & $18(23 \%)$ & $38(24 \%)$ & $34(21 \%)$ & $72(23 \%)$ \\
\hline $7-8$ years & $15(19 \%)$ & $16(20 \%)$ & $12(15 \%)$ & $13(15 \%)$ & $34(21 \%)$ & $22(14 \%)$ & $56(18 \%)$ \\
\hline $9-10$ years & $17(21 \%)$ & $15(19 \%)$ & $16(20 \%)$ & $14(18 \%)$ & $28(18 \%)$ & $34(21 \%)$ & $62(19 \%)$ \\
\hline$>10$ years & $4(5 \%)$ & $2(2 \%)$ & $5(7 \%)$ & $3(4 \%)$ & $8(5 \%)$ & $6(4 \%)$ & $14(3 \%)$ \\
\hline
\end{tabular}


Table 2 - Scale Summary $(\mathrm{N}=320)$

\begin{tabular}{|c|c|c|c|c|c|c|c|c|c|c|c|c|}
\hline \multicolumn{9}{|l|}{ Scale Items } & $\lambda$ & $\boldsymbol{\alpha}$ & $\mathbf{M}$ & SD \\
\hline \multicolumn{13}{|c|}{ Independence (IND) } \\
\hline \multicolumn{9}{|c|}{ I would rather depend on myself than others } & .83 & .65 & 4.46 & 1.23 \\
\hline \multicolumn{9}{|c|}{ My personal identify, independent of others, is important to me } & .79 & .61 & 4.74 & 1.12 \\
\hline \multicolumn{9}{|c|}{ I rely on myself most of the time, rarely on others } & .81 & .63 & 4.96 & 1.14 \\
\hline \multicolumn{9}{|c|}{ It is important that I do my job better than others } & .79 & .55 & 4.27 & 1.31 \\
\hline \multicolumn{9}{|c|}{ I enjoy being unique and different from others in many respects } & .78 & .54 & 4.24 & 1.34 \\
\hline \multicolumn{13}{|c|}{ Interdependence (INT) } \\
\hline \multicolumn{9}{|c|}{ The well-being of my group members is important for me } & .81 & .67 & 4.66 & 1.05 \\
\hline \multicolumn{9}{|c|}{ I feel good when I cooperate with my group members } & .79 & .61 & 4.71 & 1.06 \\
\hline \multicolumn{9}{|c|}{ It is my duty to take care of my family members } & .74 & .54 & 4.91 & 1.29 \\
\hline \multicolumn{9}{|c|}{ Family members should stick together, even if they do not agree } & .75 & .55 & 4.50 & 1.48 \\
\hline \multicolumn{9}{|c|}{ I enjoy spending time with my group members } & .72 & .53 & 4.20 & 1.12 \\
\hline \multicolumn{13}{|c|}{ Risk Avoidance (RSK) } \\
\hline \multicolumn{9}{|c|}{ I tend to avoid talking to strangers } & .79 & .57 & 3.90 & 1.55 \\
\hline \multicolumn{9}{|c|}{ I prefer a routine way of life to an unpredictable one full of change } & .75 & .55 & 3.94 & 1.57 \\
\hline \multicolumn{9}{|c|}{ I would not describe myself as a risk-taker } & .78 & .56 & 3.99 & 1.48 \\
\hline \multicolumn{9}{|c|}{ I do not like taking too many chances to avoid making a mistake } & .84 & .65 & 4.04 & 1.39 \\
\hline \multicolumn{9}{|c|}{ I am very cautious about how I spend my money } & .73 & .54 & 4.25 & 1.66 \\
\hline \multicolumn{13}{|c|}{ Ambiguity Intolerance (AMB) } \\
\hline \multicolumn{9}{|c|}{ I find it difficult to function without clear directions and instructions } & .82 & .62 & 4.24 & 1.55 \\
\hline \multicolumn{9}{|c|}{ I prefer specific instructions to broad guidelines } & .80 & .60 & 4.88 & 1.35 \\
\hline \multicolumn{9}{|c|}{ I tend to get anxious easily when I don't know an outcome } & .75 & .54 & 4.70 & 1.44 \\
\hline \multicolumn{9}{|c|}{ I feel stressful when I cannot predict consequences } & .78 & .58 & 4.61 & 1.46 \\
\hline I feel safe whe & I ar & in $m$ & fam & liar : & arrot & ding & & & .72 & .54 & 5.54 & 1.38 \\
\hline Interaction $\mathrm{C}$ & nto & (IC & & & & & & & & & & \\
\hline Uncomfortable & 1 & 2 & 3 & 4 & 5 & 6 & 7 & Comfortable & .80 & .63 & 4.78 & 2.33 \\
\hline Unpleasant & 1 & 2 & 3 & 4 & 5 & 6 & 7 & Pleasant & .84 & .64 & 4.66 & 2.19 \\
\hline Irritated & 1 & 2 & 3 & 4 & 5 & 6 & 7 & Relaxed & .76 & .58 & 4.14 & 2.10 \\
\hline Perceived Ser & ice & uali & (SQ & & & & & & & & & \\
\hline $\mathrm{Bad}$ & 1 & 2 & 3 & 4 & 5 & 6 & 7 & Good & .80 & .64 & 4.44 & 1.91 \\
\hline Poor & 1 & 2 & 3 & 4 & 5 & 6 & 7 & Excellent & .85 & .67 & 4.29 & 2.02 \\
\hline $\begin{array}{l}\text { Below } \\
\text { Expectation }\end{array}$ & 1 & 2 & 3 & 4 & 5 & 6 & 7 & $\begin{array}{l}\text { Above } \\
\text { Expectation }\end{array}$ & .83 & .65 & 4.22 & 1.94 \\
\hline Satisfaction ( & & & & & & & & & & & & \\
\hline Dissatisfied & 1 & 2 & 3 & 4 & 5 & 6 & 7 & Satisfied & .85 & .66 & 4.10 & 1.85 \\
\hline Unhappy & 1 & 2 & 3 & 4 & 5 & 6 & 7 & Нарру & .82 & .62 & 4.41 & 1.85 \\
\hline Displeased & 1 & 2 & 3 & 4 & 5 & 6 & 7 & Pleased & .83 & .64 & 4.30 & 1.82 \\
\hline
\end{tabular}




\begin{tabular}{lllll}
\hline Scale Items & $\boldsymbol{\lambda}$ & $\boldsymbol{\alpha}$ & $\mathbf{M}$ & SD \\
\hline Perceived Cultural Distance (PCD) & & & & \\
For the person shown in the picture: & & & \\
- Ethnicity is very different from me & .78 & .59 & 4.81 & 1.33 \\
- Nationality is very different from me & .82 & .64 & 4.64 & 1.29 \\
- Language is very different from me & .77 & .57 & 4.12 & 1.40 \\
- Customs are very different from me & .81 & .62 & 4.43 & 1.24 \\
- Religious beliefs are very different from me & .80 & .61 & 4.22 & 1.10 \\
Consumer Ethnocentrism (CET) & & & & \\
We should not buy foreign products, because it hurts our economy & .83 & .67 & 4.24 & 1.79 \\
Only products that are unavailable in our country should be imported & .82 & .65 & 4.06 & 1.72 \\
Purchasing foreign products allows other countries to get rich off us & .88 & .72 & 4.14 & 1.72 \\
I may cost me in the long run but I support my own country's products & .86 & .71 & 3.94 & 1.67 \\
Intercultural Competence (ICC) & & & & \\
I feel comfortable dealing with people whose: & & & & \\
- Ethnicity is very different from me & .84 & .66 & 4.41 & 1.66 \\
- Nationality is very different from me & .82 & .64 & 4.43 & 1.65 \\
- Language is very different from me & .83 & .65 & 3.91 & 1.63 \\
- Customs are very different from me & .80 & .62 & 4.04 & 1.68 \\
- Religious beliefs are very different from me & .81 & .63 & 4.01 & 1.70 \\
\hline
\end{tabular}

Note: $\lambda=$ Standardized Factor Loading; $\alpha=$ Squared Multiple Correlations; $\mathrm{M}=$ Mean; $\mathrm{SD}=$ Standard Deviation 
Table 3 - Correlations Matrix $(\mathbf{N}=\mathbf{3 2 0})$

\begin{tabular}{|c|c|c|c|c|c|c|c|c|c|c|c|}
\hline & IND & INT & RSK & AMB & IC & SQ & SAT & CET & ICC & Mean & SD \\
\hline Independence (IND) & 1.00 & - & - & - & - & - & - & - & - & 5.33 & 0.81 \\
\hline Interdependence (INT) & .05 & 1.00 & - & - & - & - & - & - & - & 5.60 & 0.76 \\
\hline Risk Aversion (RSK) & -.07 & $.19^{* *}$ & 1.00 & - & - & - & - & - & - & 4.02 & 1.06 \\
\hline Ambiguity Intolerance (AMB) & -.07 & $.28^{* *}$ & $.45^{* *}$ & 1.00 & - & - & - & - & - & 4.79 & 1.07 \\
\hline Interaction Comfort (IC) & $-.18^{* *}$ & -.03 & .06 & .00 & 1.00 & - & - & - & - & 4.53 & 1.61 \\
\hline Service Quality (SQ) & $-.19^{* *}$ & .03 & .01 & -.05 & $.38^{* * *}$ & 1.00 & - & - & - & 4.32 & 1.78 \\
\hline Satisfaction (SAT) & $-.14^{* *}$ & .00 & .08 & .06 & $.31^{* * *}$ & $.39^{* * *}$ & 1.00 & - & - & 4.27 & 1.84 \\
\hline Consumer Ethnocentrism (CET) & -.10 & $.16^{* *}$ & .01 & $.17^{* *}$ & -.07 & -.06 & -.09 & 1.00 & - & 4.10 & 1.10 \\
\hline Intercultural Competence (ICC) & $.11^{*}$ & $.14^{* *}$ & $-.16^{* *}$ & $-.15^{* *}$ & -.05 & .01 & -.01 & $-.27^{* * *}$ & 1.00 & 5.16 & 1.19 \\
\hline Composite Reliability (CR) & .84 & .80 & .83 & .81 & .85 & .88 & .90 & .92 & .89 & & \\
\hline $\begin{array}{l}\text { Average Variance Extracted } \\
\text { (AVE) }\end{array}$ & .64 & .58 & .61 & .60 & .64 & .68 & .69 & .72 & .67 & & \\
\hline
\end{tabular}


Table 4 - Hierarchical Regression Output

Dependent Variable: Interaction Comfort

\begin{tabular}{|c|c|c|c|c|c|c|}
\hline & Independent Variables & 1 & 2 & 3 & 4 & Result \\
\hline H1 (-) & Cultural Distance (PCD) & - & $-0.33^{* * *}$ & $-0.39^{* * *}$ & $-0.40^{* * *}$ & Supported \\
\hline $\mathrm{H} 2(+)$ & $\begin{array}{l}\text { Service Outcome (OUT) } \\
(0=\text { Failure, } 1=\text { Success })\end{array}$ & - & $0.40^{* * *}$ & $0.42^{* * *}$ & $0.43^{* * *}$ & Supported \\
\hline $\mathrm{H} 3 \mathrm{a}(+)$ & Independence (IND) & - & 0.07 & $0.19^{* *}$ & $0.31^{* * *}$ & Supported \\
\hline $\mathrm{H} 4 \mathrm{a}(-)$ & Interdependence (INT) & - & -0.07 & -0.09 & $-0.12^{*}$ & Supported \\
\hline H5a $(-)$ & Risk Aversion (RSK) & - & -0.02 & $-0.18^{* *}$ & $-0.23^{* *}$ & Supported \\
\hline H6a (-) & Ambiguity Intolerance (AMB) & - & -0.06 & $-0.24^{* *}$ & $-0.20^{* *}$ & Supported \\
\hline $\mathrm{H} 3 \mathrm{~b}(+)$ & PCD * Independence & - & - & $-0.29^{* *}$ & $-0.36^{* * *}$ & Supported \\
\hline $\mathrm{H} 4 \mathrm{~b}(+)$ & PCD * Interdependence & - & - & 0.08 & 0.02 & Not Supported \\
\hline $\mathrm{H} 5 \mathrm{~b}(+)$ & PCD * Risk Aversion & - & - & $0.20^{* *}$ & $0.25^{* *}$ & Supported \\
\hline $\mathrm{H} 6 \mathrm{~b}(+)$ & PCD * Ambiguity Intolerance & - & - & $0.21^{* *}$ & $0.22^{* * *}$ & Supported \\
\hline $\mathrm{H} 3 \mathrm{c}(+)$ & OUT $*$ Independence & - & - & - & $0.18^{* *}$ & Supported \\
\hline $\mathrm{H} 4 \mathrm{c}(-)$ & OUT * Interdependence & - & - & - & -0.04 & Not Supported \\
\hline $\mathrm{H} 5 \mathrm{c}(-)$ & OUT * Risk Aversion & - & - & - & $-0.22^{* *}$ & Supported \\
\hline \multirow[t]{2}{*}{ H6c (-) } & OUT * Ambiguity Intolerance & - & - & - & $-0.19^{* *}$ & Supported \\
\hline & Control Variables & & & & & \\
\hline $\mathrm{C} 1$ & Gender $(0=$ Female, $1=$ Male $)$ & -0.01 & 0.08 & 0.08 & 0.06 & \\
\hline $\mathrm{C} 2$ & Ethnicity $(1=$ Chinese, $2=$ Other $)$ & -0.04 & 0.00 & -0.01 & 0.00 & \\
\hline C3 & Age (Years) & -0.06 & -0.01 & -0.02 & -0.01 & \\
\hline $\mathrm{C} 4$ & Work Experience (Years) & -0.03 & -0.02 & -0.01 & -0.02 & \\
\hline C5 & Consumer Ethnocentrism & -0.06 & $-0.08^{*}$ & $-0.10^{*}$ & $-0.11^{*}$ & \\
\hline \multirow[t]{3}{*}{ C6 } & Intercultural Competence & 0.04 & 0.04 & 0.05 & 0.05 & \\
\hline & Adjusted R-square Value & 0.05 & $0.23^{* * *}$ & $0.36^{* * *}$ & $\mathbf{0 . 4 3} 3^{* * *}$ & \\
\hline & Change in Adj. $\mathbf{R}^{2}$ Value & - & $.18^{* * *}$ & $.13^{* * *}$ & $.07^{* *}$ & \\
\hline
\end{tabular}

${ }^{*} p<.05 ; * * p<.01 ; * * * p<.001$ 


\section{Appendix 1 - Experiment Scenarios}

\begin{tabular}{|c|c|}
\hline $\begin{array}{l}\text { Basic } \\
\text { Scenario }\end{array}$ & $\begin{array}{l}\text { One day it is a busy evening at a popular restaurant when a } \\
\text { customer walks in without a booking and asks for a table. The } \\
\text { waiter requests the customer to wait for a while but being in a } \\
\text { hurry the customer insists on getting a table immediately. }\end{array}$ \\
\hline $\begin{array}{l}\text { Service } \\
\text { Failure }\end{array}$ & $\begin{array}{l}\text { - There are no vacant tables and the customer has to wait for } \\
\text { almost } 15 \text { minutes, before being seated. } \\
\text { - While the customer looks at the menu to decide what to order, } \\
\text { the waiter simply walks away and makes no suggestions. } \\
\text { - Being a busy evening, the food arrives after almost } 30 \text { minutes } \\
\text { and all this time, the customer keeps calling the waiter to find } \\
\text { out about the order. } \\
\text { After the food is served, the customer realizes that it is the } \\
\text { wrong order but the waiter argues with the customer to prove } \\
\text { that the food is exactly as per the order. }\end{array}$ \\
\hline $\begin{array}{l}\text { Service } \\
\text { Success }\end{array}$ & $\begin{array}{l}\text { - The waiter manages to find a vacant table and the customer } \\
\text { has to wait only for a few minutes before being seated. } \\
\text { - While the customer looks at the menu to decide what to order, } \\
\text { the waiter stands next and makes many useful suggestions. } \\
\text { - Despite being a busy evening, the food arrives within a few } \\
\text { minutes and all this time the waiter keeps the customer } \\
\text { informed about the order. } \\
\text { After the food is served, the customer realizes that it is the } \\
\text { wrong order but the waiter apologizes for the mistake and } \\
\text { promptly replaces it with the correct order. }\end{array}$ \\
\hline
\end{tabular}

